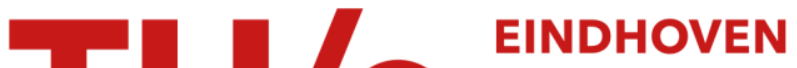 UNIVERSITY OF TECHNOLOGY
}

\section{Capture and concentration of light to a spot in plastic lightguides by circular luminophore arrangements}

\section{Citation for published version (APA):}

Bruijnaers, B. J., Schenning, A. P. H. J., \& Debije, M. G. (2015). Capture and concentration of light to a spot in plastic lightguides by circular luminophore arrangements. Advanced Optical Materials, 3(2), 257-262.

https://doi.org/10.1002/adom.201400414

DOI:

10.1002/adom.201400414

Document status and date:

Published: 01/01/2015

\section{Document Version:}

Publisher's PDF, also known as Version of Record (includes final page, issue and volume numbers)

\section{Please check the document version of this publication:}

- A submitted manuscript is the version of the article upon submission and before peer-review. There can be important differences between the submitted version and the official published version of record. People interested in the research are advised to contact the author for the final version of the publication, or visit the $\mathrm{DOI}$ to the publisher's website.

- The final author version and the galley proof are versions of the publication after peer review.

- The final published version features the final layout of the paper including the volume, issue and page numbers.

Link to publication

\section{General rights}

Copyright and moral rights for the publications made accessible in the public portal are retained by the authors and/or other copyright owners and it is a condition of accessing publications that users recognise and abide by the legal requirements associated with these rights.

- Users may download and print one copy of any publication from the public portal for the purpose of private study or research.

- You may not further distribute the material or use it for any profit-making activity or commercial gain

- You may freely distribute the URL identifying the publication in the public portal.

If the publication is distributed under the terms of Article $25 \mathrm{fa}$ of the Dutch Copyright Act, indicated by the "Taverne" license above, please follow below link for the End User Agreement:

www.tue.nl/taverne

Take down policy

If you believe that this document breaches copyright please contact us at:

openaccess@tue.nl

providing details and we will investigate your claim. 


\title{
Capture and Concentration of Light to a Spot in Plastic Lightguides by Circular Luminophore Arrangements
}

\author{
Bardo J. Bruijnaers, Albertus P. H.J. Schenning, and Michael G. Debije*
}

In this work, it is demonstrated how organic dichroic fluorescent dye molecules embedded in a polymerizable liquid crystal host can be aligned in circular patterns so that sunlight is captured by the fluorophores and the emissions of the dye molecules are all directed primarily towards either a small spot along the edge or towards the center of the plastic lightguide for maximal concentration. By attaching a photovoltaic cell to this spot, the concentrated light can be converted into electricity.

\section{Introduction}

Capture and control of the distribution of collected light and energy within natural systems ${ }^{[1-5]}$ has inspired researchers to try and apply the same concepts to man-made devices to increase the accuracy of lighting and optical communication systems and the efficiency of solar energy generators, for example. Many manufactured devices rely on the efficiency of these light directing constructs, including solar pumped lasers, ${ }^{[6]}$ photobioreactors, ${ }^{[7]}$ solar lighting systems, ${ }^{[8]}$ switchable widows, ${ }^{[0]}$ hydrogen production devices, ${ }^{[10]}$ organic and inorganic LEDs, ${ }^{[11,12]}$ microreactors, ${ }^{[13]}$ synthetic fuels generators from biomass, ${ }^{[14]}$ and concentrating solar energy systems: ${ }^{[15]}$ all have at their base the necessity of collecting and selectively directing light. A great number of techniques have been used to manage light propagation in materials. ${ }^{[16]}$ Among them are the use of mirrors, both organic and inorganic, lenses and prisms ${ }^{[17]}$ plasmonic systems; ${ }^{[18]}$ changes in refractive index; ${ }^{[19]}$ circular porphyrin arrays:;20] metamaterials; ${ }^{[21]}$ and molecular assemblies. ${ }^{[22]}$ However, it remains a challenge to fabricate materials over large surface areas capable of collecting sunlight and directing towards a specific location in an inexpensive way.

We now have developed such systems using self-assembling host liquid crystals (LCs) doped with luminescent dye molecules. With absorption and emission events, we may avoid the standard thermodynamic limits imposed by etendue, ${ }^{[23]}$ and achieve a redirection of light into a lightguide that is not otherwise possible with geometric optics. We make use of curved and circular dye arrangements in self-assembling materials to collect and direct sunlight to specific locations. The concept

B. J. Bruijnaers, Prof. A. P. H. J. Schenning, Dr. M. G. Debije

Functional Organic Materials and Devices

Department of Chemical Engineering and Chemistry

Eindhoven University of Technology

5600 , MB Eindhoven, The Netherlands

E-mail:m.g.debije@tue.nl

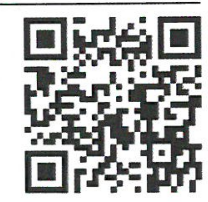

DOI: 10.1002/adom.201400414 of light direction is demonstrated in one possible model device, a luminescent solar concentrator (LSC). ${ }^{[24,25]}$ An LSC, a polymer or glass plate that contains luminophores, absorbs incoming sunlight (including indirect sunlight) through the top surface of the lightguide. The luminophores then emit light, of which a significant fraction is trapped inside the plate by total internal reflection and transported towards the sides of the LSC. By attaching photovoltaic (PV) cells to LSC edges, the exiting light can be collected and converted into electricity. Since relatively small PV cells are required to harvest light from a large surface area, the LSC has the capability to become an inexpensive solar energy harvesting system which could find deployment in areas otherwise inaccessible to standard silicon-based solutions. ${ }^{[25]}$

The standard LSC device emits light to each edge equally, requiring the use of multiple PV cells. ${ }^{[25,26]}$ If the light that is emitted by embedded luminophores of a LSC were to be focused towards smaller, specific regions on the edge or even inside the LSC, smaller, more efficient PV cells could be used improving performance. Organic luminophores are often dichroic, meaning that they are anisotropic in both absorption and emission. ${ }^{[27]}$ The aligned dichroic dyes absorb incident light and re-emit this energy as light of a longer wavelength predominantly in a direction perpendicular to the transition dipole. ${ }^{[28,29]}$ Rather than a random distribution of dye molecules normally created by generating LSCs from an acrylate solution, we orient the fluorophores. Alignment of the organic dye is achieved using a photoreactive LC host material and simple rubbing patterns in alignment layers to order the molecules. The basic design concept is illustrated in Figure 1.

In this work, novel fluorescent dye thin films using "theater" and "quarter circle" alignments with good curved alignment $(S=0.5-0.6)$ on large substrates $\left(100 \times 100 \mathrm{~mm}^{2}\right)$ with highly directional emission of light focusing to a small region of a lightguide edge can be realized and clearly visualized by photos with a light intensity camera and could be converted to electricity by applied PV cells. Finally, a centrally focused lightguide was fabricated which generates the highest concentration factor.

\section{Results and Discussion}

In order to align the fluorescent dyes, we made use of a photoreactive LC host. By applying a polyvinyl alcohol (PVA) layer to the surface of the polymer lightguide followed by rubbing with a velvet cloth in linear or circular fashion. Then, LC/fluorescent dye mixtures are solution-deposited and self-assemble 


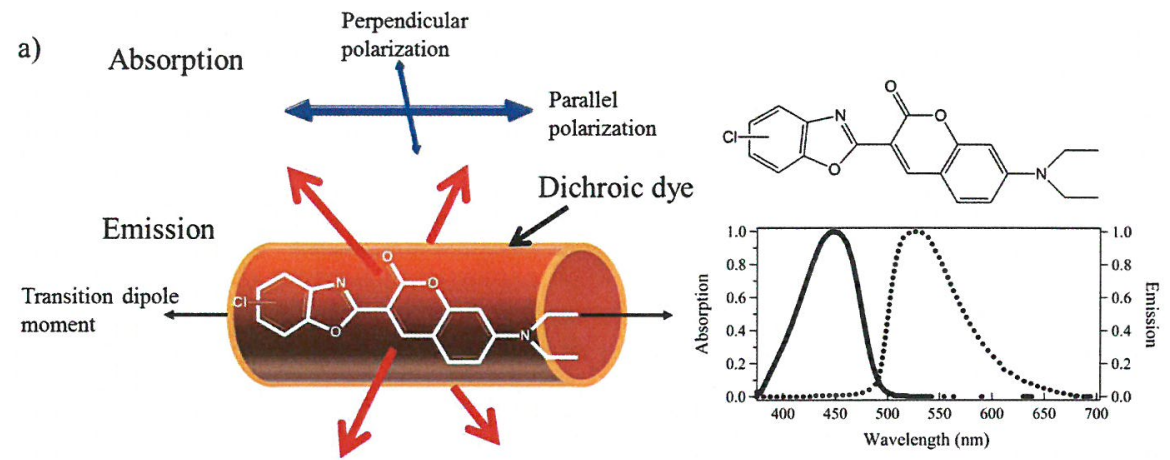

b)

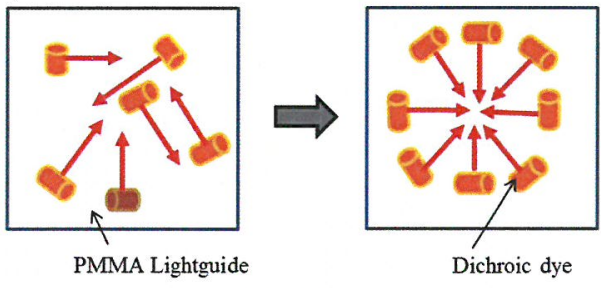

Top view c)

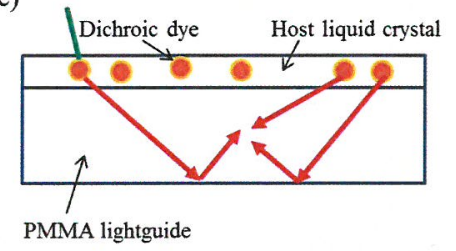

Side view

Figure 1. a) Schematic representation of the anisotropic nature of the absorption of different polarization directions of light (blue arrows, with the size of the arrow representing the amount of light absorbed) and primary emission directions (red arrows) of dichroic dyes. Also shown is the structure of the coumarin derivative used in this work and normalized absorption and edge emission spectra of the dye in an acrylate on a PMMA lightguide. b) Concept image of enhanced light focusing using alignment of dichroic dyes. (Left) Standard isotropic dye alignment; (Right) aligned dichroic dye molecules. Emission light is shown in red. c) Side view of lightguide with thin aligned dye layer on top of a clear plastic waveguide. Incident light shown as a green line, emission light in red.

following the alignment direction of the underlying PVA layer forming largely transparent films. The thin solid polymer coatings are then created by exposing the layer to UV light, inducing cross-linking between the reactive monomers. The first aligned dye lightguides were prepared in the "theater" and "quarter circle" alignments on $100 \times 100 \times 5 \mathrm{~mm}^{3}$ PMMA lightguides shown in Figure 2. Isotropic and planar samples were also produced for comparison, and are found in Table 1.

First, we have determined if the desired dye alignment patterns within the LC film was obtained. Photographs

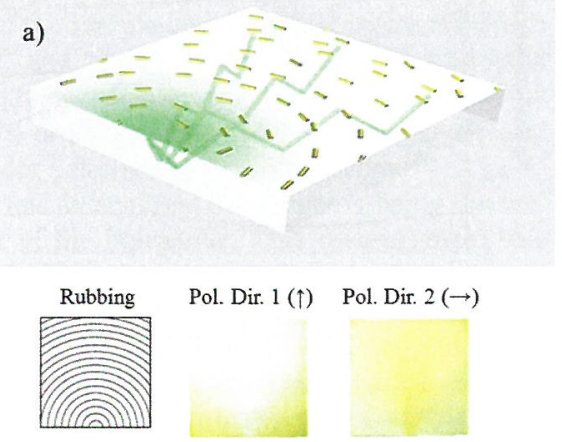

demonstrating the alignment of the quarter circle, theater, isotropic, and planar samples under single linear polarizers are displayed in Figure 2 and Table 1. From the photographic images of the samples under polarized light, we can see 'colored' and 'uncolored' regions: the colored (yellow) regions correspond to areas where the transition dipoles of the dyes are aligned parallel to the polarization direction and have absorbed a fraction of the incoming light, and uncolored (whitish) where perpendicular. The colors obtained are consistent with the intended alignments. Absorbance spectra were measured using polarized

b)

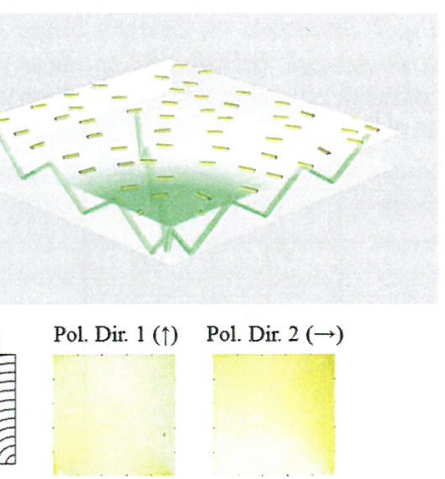

Figure 2. (Top) Schematic representation of the functionality of the a) theater $(T H)$ and b) quarter circle $(Q C)$ alignments described in this work. Fluorescent dyes are represented by yellow cylinders, and the green lines dye emission and the green tinted regions are areas of enhanced light concentration. (Bottom) Photographs of representative backlit samples of quarter circle $(Q C)$ and theater $(T H)$ viewed under a linear polarizer in two different directions. Polarization direction 1 is orthogonal to polarization direction 2 and indicated by the arrows. The yellow color indicates regions of light absorption by the polarizers. 
optical microscopy at $50 \mathrm{x}$ magnification. The order parameters of the isotropic sample showed some small local order with an order parameter of about 0.17 (polarized microscopy reveals short range local order in the isotropic sample: macroscopic order parameters were near zero): planar, $P L(0.52)$, theater, TH $(0.53)$ and quarter circle, $Q C(0.40)$ were about 0.5 , consistent with earlier results for this dye. ${ }^{[28]}$ These measurements reveal that the desired alignment of the dyes in the polymer coating is obtained.

Subsequently, we investigated the ability of the dichroic luminophores to direct light in the polymer lightguide by measuring the light output from the edges of LSCs exposed from overhead to light from a solar simulator using a light intensity camera. The expected focal points for $T H$ and $Q C$ alignments are depicted in green in Figure 3a, b: below these cartoons are edge emission photographs from the quarter circle and theater patterns. One would expect emission from these points to be greatest as there are the greatest numbers of dye molecule emission dipoles directing their emission towards these locations. Indeed, the light emission intensities correspond exactly to the predicted output based on the dye alignment. To confirm these observations, we measured the emission profiles for all four edges for four TH and four $Q C$ aligned samples to determine reproducibility of both the alignment and measurement methods; the results are found in Figure 3c. The images clearly show that the edge emission resulting from dye alignments agree with the predictions and are reproducible and that, qualitatively, there is focusing of the wave-guided light towards the expected focal points.

In order to show that the concentrated light can also be converted into electricity, the emissions along the edges of the lightguides were also measured using a silicon PV cell with a photosensitive area of $20 \times 5 \mathrm{~mm}^{2}$ placed at five locations along each edge of the sample: an example of measurement locations

Table 1. Photographs of isotropic (I) and uniaxial linear (L) samples under polarized light of the direction indicated by the arrows. The yellow color indicates regions of light absorption by the polarizers.

\begin{tabular}{|c|c|c|}
\hline Sample & Pol. Dir. 1 & Pol. Dir. 2 \\
\hline & $(\uparrow)$ & $(\rightarrow)$ \\
\hline \multicolumn{3}{|l|}{ I } \\
\hline L & & \\
\hline & & \\
\hline nininili & & \\
\hline
\end{tabular}

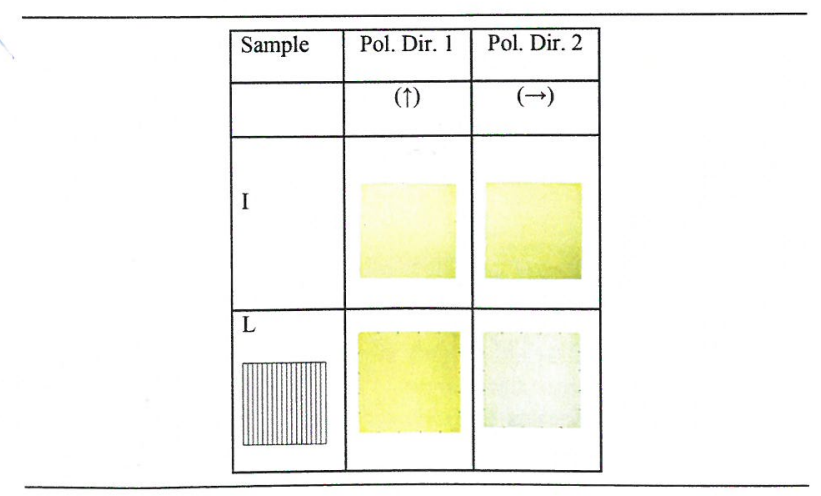

along edges of the $P L, T H$ and $Q C$ samples are seen at the top of Figure 4. The short circuit current $I_{\mathrm{SC}}$ and open circuit voltage $V_{O C}$ were measured at each of the five locations along all edges

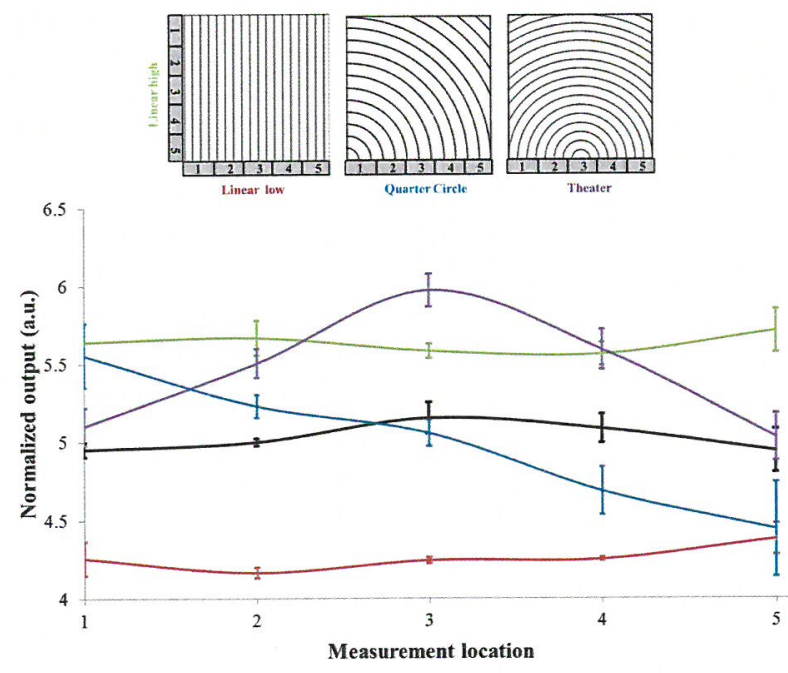

Figure 4. (Top) Schematic of the Linear, Quarter Circle and Theater alignments and locations of the photovoltaic cells for edge output measurement. (Bottom) Edge output measured using the photovoltaic cell at different spots along the edge of LSCs, spot 1 being the leftmost measurement location and spot 5 being the rightmost measurement location. Lines are drawn between the five measurement spots of each edge to aid the eye. The error bars show the standard deviation. Black = isotropic, Green = planar, higher output edge, Red = planar, lower output edge, Purple $=$ theater alignment and Blue $=$ quarter circle alignment. 
of the LSCs. To eliminate any differences in absorbance between samples, the total short circuit currents from all the measurement locations were normalized to 100 for each sample. Since there are five measurement regions on each edge and four edges per sample, the normalization means that for an LSC that emits completely isotropically, every measurement location should have an output value of 5 . The emission results from edge 1 (or two edges of the planar sample) were averaged and are displayed at the bottom of Figure 4 . The output at every measurement location of the isotropic and each individual edge of the planar LSCs is about equal, as expected. The output ratio of light emitted from the edge parallel to the alignment to that from the edge perpendicular $\left(\mathrm{E}_{\|} / \mathrm{E}_{\perp}\right)$ in the planar sample was found to be 1.3 , in reasonable agreement with the measured order parameter of 0.5. ${ }^{[28]}$ The TH aligned LSCs have a focal point with high output at the center of their edge. The output at the central focus point of the $T H$ aligned edge is about 1.2 times that of the isotropic edge. The $Q C$ aligned edge shows a pronounced decrease in output from the left side to the right side. These results clearly show it is possible to collect sunlight and direct emission light towards specific locations at the edge of lightguides and convert it into electricity. ${ }^{[28]}$

To illustrate the full potential of dye alignment, the light was also directed to the center of the lightguide by fabricating a circular sample. In Figure 5, pictures of the $100 \times 100 \times$ $5 \mathrm{~mm}^{3}$ circularly aligned LSCs under single and crossed linear polarizers are displayed. The photographs of the sample under polarized light show "colored" and "uncolored" regions matching the rubbing conditions of the lightguides as previously discussed for the TH and QC samples. The alignment is further supported by the photograph of the sample under crossed polarizers which displays clear "dark" and "light" regions, also suggesting good alignment. This high degree of alignment was confirmed by measurements of the order parameter of $0.5-0.6$ in the circular aligned samples under polarized optical microscopy. ${ }^{[28]}$

In a next step, it was determined if the light is being concentrated to the center of the lightguide. This measurement was done indirectly by drilling a cone shape hole in the center of an isotropic and a circular aligned plate. The cone shape was chosen to enhance outcoupling of light from the lightguide. One of two different PV cells was placed with its photosensitive area pointing down on the top surface of the LSC at the position of the cone (see Figure 5, top). The silicon PV cell had an area of $20 \times 5 \mathrm{~mm}^{2}$ while the second type III-V PV cell had an area of $10 \times 10 \mathrm{~mm}^{2}$. The LSCs were illuminated from above by the solar simulator. In Figure 6, the measured $I_{\mathrm{SC}}$ of the two PV cells are displayed for both the isotropic and circular aligned devices; as expected, $V_{O C}$ remained constant. The $I_{\mathrm{SC}}$ was about $33 \%$ higher for the circular aligned devices than for the unaligned isotropic devices for both PV cell types (31.6\% for silicon and $34.2 \%$ for type III-V). This experiment shows proof of principle in collecting sunlight and redirecting light to a central point where it is converted into electricity by a centrally-mounted PV cells. Circular alignment could provide additional benefits of minimizing light transport distances, and in so doing also minimize the number of reabsorption events, a primary loss mechanism in LSC devices. ${ }^{[25]}$

\section{Conclusion and Outlook}

In this work, we have demonstrated enhanced control over light emission directions of dichroic dyes using simple production methods applicable to large surface areas. Measurement of the output in the center of a $100 \times 100 \times 5 \mathrm{~mm}^{3}$ circular aligned dye 


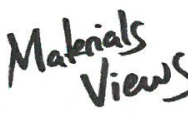

www.MaterialsViews.com
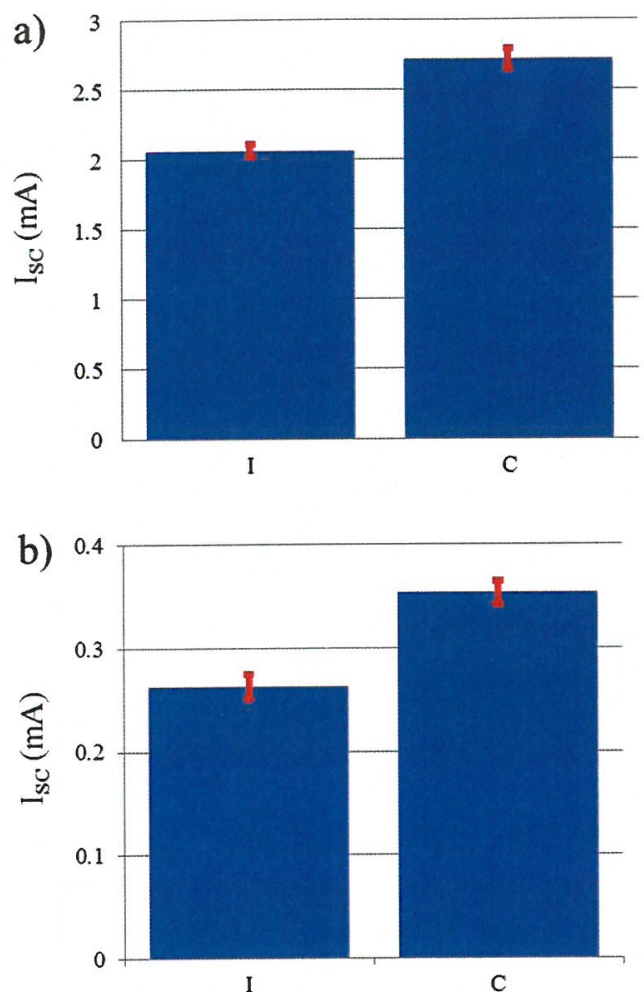

Figure 6. The measured short circuit current of a) silicon and b) type III-V PV cell placed on top of three isotropic $(I)$ and three circular (C) aligned lightguides.

lightguide showed about $33 \%$ higher emission from the center than that of an isotropic dye sample. We have demonstrated the first effective concentration of light towards specific regions at the center or localized edge regions of an LSC and converted into electricity. We expect that a significant improvement can be made when using better aligned system employing more appropriate PV cells. The next step in the development of the central-mounted LSC system will require the manufacture and mounting of small, flexible PV cells to the inner wall of the hole in the lightguide center with an index matching adhesive, and mirrors placed at the lightguide edges. Employment of circular aligned dyes employing photocatalytic reaction centers at the focus of the lightguides rather than PV cells is an interesting area of future work. Using more highly aligning dyes ${ }^{[30]}$ or dye complexes ${ }^{[31-33]}$ should also improve concentrations that can be achieved. One may also envision even more complex patterning to generate alternative concentration regimes. ${ }^{[34]}$

The ability to manage light emission over large area could find widespread use in a variety of other devices, including microreactors, lasers, organic LEDs and solar lighting. This work is in progress.

\section{Experimental Section}

Thin film LSCs were produced by coating edge polished $100 \times 100 \times$ $5 \mathrm{~mm}^{3}$ PMMA substrates (PlanoPlastics) with a $5 \mathrm{wt} \%$ PVA (Sigma-

Aldrich)/ water solution by spin casting at 1000 RPM for $30 \mathrm{~s}$. The PVA layer was rubbed with a velvet cloth in the desired alignment pattern. For isotropic LSCs, the rubbing step was omitted. A mixture containing $98.5 \mathrm{wt} \%$ of LC (Paliocolor LC 242, BASF), $0.5 \mathrm{wt} \%$ of a coumarin derivative dye ${ }^{[32]}$ (see Figure 1) with a fluorescence quantum yield $>90 \%, 0.5$ wt $\%$ surfactant (2-(n-ethylperfluorooctanesulfonamido)-ethyl methacrylate stabilized, Acros) and 0.5 wt $\%$ of photo-initiator (Irgacure 184, Ciba) dissolved in Xylene (Biosolve) (45:55 weight ratio solid: solvent) was spin cast on top of the PVA layer at 1000 RPM for $30 \mathrm{~s}$. The LSCs were then placed on a hotplate at $80^{\circ} \mathrm{C}$ for $10 \mathrm{~s}$ to evaporate the solvent and assist LC alignment and subsequently photocured for 10 min under nitrogen flow using low intensity UV radiation from a Philips Home Solaria HB 172 to form a cross-linked, solid film.

Four quarter circle ( $Q C$ alignment) and four theater ( $T H$ alignment) LSCs were created by manual rubbing around a fixed point at the corner, and center of one edge of the substrate, respectively. Two linear ( $L$ alignment) samples were produced by rubbing in a straight line. Two isotropic (I alignment) samples were made by spin casting the LC solution directly on unrubbed PVA. For the circular, C, aligned samples, the PVA coated substrate was placed on a spin coater and rubbed with a velvet cloth held in the center of the spinning sample for about $10 \mathrm{~s}$ at a 100 RPM.

Absorbance spectra of the samples were measured using a Shimadzu UV-3102 PC spectrophotometer. Peak absorption was measured using incident linearly polarized light both parallel $\left(A_{\|}\right)$and perpendicular $\left(A_{\perp}\right)$ to the dye alignment. The measure of alignment of the dye molecules is determined by calculating the optical order parameter $(S)$ for absorption using Equation (1).

$$
S=\frac{A_{\|}-A_{\perp}}{A_{\|}+2 A_{\perp}}
$$

Perfect uniaxial order of the absorbing dipoles of the fluorescent dye molecules would be described as $S=1$ and a completely isotropic system would correspond to $S=0$. The maximal $S$-value of different rod-like LCs at room temperature reported are in the order of $0.6-0.7 .{ }^{[35}$ Polarized optical microscopy was performed using a HR2000+ high-resolution spectrometer (Ocean Optics), mounted on a DM6000 M microscope (Leica) at $50 \times$ magnification.

Thicknesses of the films were measured using a Fogale Nanotech Zoomsurf 3D interferometer. The average thickness per alignment type $(I=4.27 \mu \mathrm{m}, L=3.94 \mu \mathrm{m}, T H=3.68 \mu \mathrm{m}$ and $\mathrm{QC}=3.79 \mu \mathrm{m})$ indicates the isotropic LSCs are roughly $8 \%$ to $14 \%$ thicker than the aligned LSCs. However, the resulting difference in absorbance was only $3 \%$. The circular pattern layers were the same thickness as the isotropic samples. The thickness of the PVA alignment layer was measured several times and was found to be about $0.4 \mu \mathrm{m}$ ( $\pm 10 \%$ of the total thickness).

Edge outputs of the $Q C$ and TH LSCs were measured using a light intensity camera (Radiant Imaging PM series Imaging Colorimeter) to obtain visual evidence of the light guiding properties by recording both the light intensity and color of every pixel. The LSCs were illuminated from above using a collimated light source from a $300 \mathrm{~W}$ solar simulator (Lot Oriel) with added scatter foils to provide a homogeneously illuminated area at a distance of about $30 \mathrm{~cm}$. The three edges that were not measured were painted black to minimize reflections. A mask was placed on top of the lightguide so only the edge of interest was exposed to the camera lens located orthogonal to the center of the emitting edge and tilted down at an angle of $22.5^{\circ}$ in order to collect the edge emission (almost no light exits the lightguide perfectly horizontally: see Figure 7a).

Additional measurements of light output at the edges of the LSCs were done by pressing a PV cell with an area of $20 \times 5 \mathrm{~mm}^{2}$ against the lightguide at different locations along the edges of the LSCs while the device was illuminated from overhead by a K. H. Steuernagel Lichttechnik $\mathrm{GmbH}$ SolarConstant 1200 equipped with a metal halide $1200 \mathrm{~W}$ light source. A small mask was used to avoid direct illumination of the solar cell by the light source (see Figure $7 b$ for the setup). The edges of the LSCs that were not being measured were left open. Since the edge of the lightguide is $100 \times 5 \mathrm{~mm}^{2}$ and the solar cell was $20 \times 5 \mathrm{~mm}^{2}$, the edge was divided into exactly five sections, each measured separately. Both 
a)

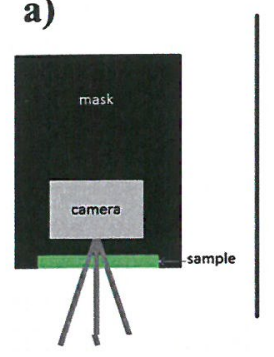

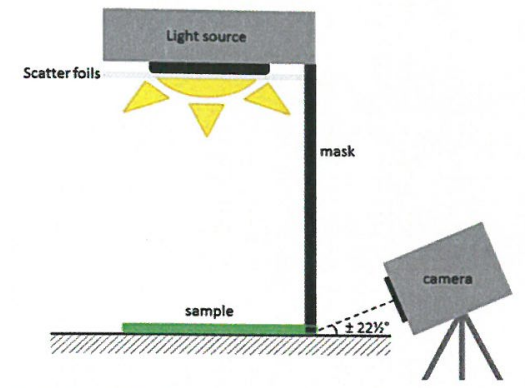

b)
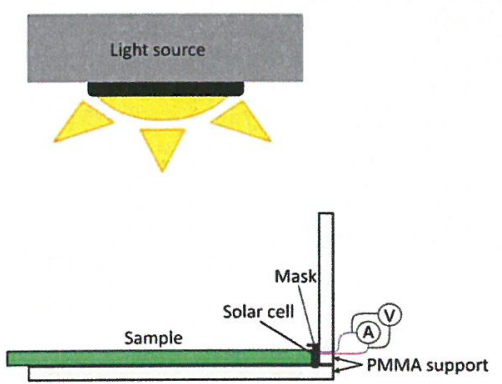

Figure 7. a) Front view (left) and side view (right) of the measurement setup used to measure the light direction abilities of the LSCs using the light intensity camera. b) Schematic side view of the edge output measurement setup using a small solar cell.

the open circuit voltage (measured at 0 current $\left(V_{o c}\right)$ ) and short circuit current (measured at 0 voltage $\left(I_{\mathrm{sc}}\right)$ ) were recorded at the five different locations on all four edges of the LSCs. The $I_{\text {sc }}$ was used as a direct measure of the light output power of the LSC.

Additional edge emission measurements were carried out on smaller $\left(5 \times 5 \times 0.5 \mathrm{~cm}^{3}\right)$ waveguides with isotropic, circular, and planar samples by illuminating the surface with a $300 \mathrm{~W}$ solar simulator with filters to approximate the 1.5AM (global) solar spectrum (Lot-Oriel), at a distance of about $15 \mathrm{~cm}$ from the lightguide. Edge emissions of the lightguides were measured by an SLMS 1050 integrating sphere (Labsphere) with a diode array detector (RPS900, International Light). ${ }^{[28]}$ The total edge emission from all four sides of six samples of each type ( 18 LSCs in total) were the same after correction for increased absorption in the isotropic device.

For the measurement of the output of the circular aligned and isotropic LSCs, a cone shape hole with edge slope $45^{\circ}$ was drilled in the center of the LSC. Light traveling through the lightguide encounters the unpolished cone's PMMA-air interface and a fraction will be refracted out of the lightguide. In order to measure the output at the cone, a small solar cell was placed face down on top of the LSC at the location of the cone. Two different types of solar cells were used; a silicon cell and a type III-V cell (Emcore). The back of each solar cell was masked. The LSC was illuminated from the top using the $1200 \mathrm{~W}$ light source. The $V_{o c}$ and $I_{\mathrm{sc}}$ of the solar cells were measured.

\section{Acknowledgements}

The authors wish to thank Jeroen ter Schiphorst for his work on the images found in Figures 2 and 5 of this document.

Received: September 16, 2014

Revised: October 28, 20414 Published online: November 21, 2014
[1] A. D. Grinnell, P. M. Narins, F. T. Awbrey, W. M. Hamner P. P. Hamner, J. Exp. Biol. 1988, 134, 61.

[2] P. Vukusic, I. Hooper, Science 2005, 310, 1151.

[3] T. J. Wardill, P. T. Conzalez-Bellido, R. J. Crook, R. T. Hanlon, P. Roy. Soc. B-Biol. Sci. 2012, 279, 4243.

[4] A. Gal, V. Brumfeld, S. Weiner, L. Addadi, D. Oron, Adv. Mater. 2012, 24, 77.

[5] a) S. Niwa, L.-J. Yu, K. Takeda, Y. Hirano, T. Kawakami, Z.-Y. Wang Otomo, K. Miki, Nature 2014, 508, 228; b) F. Fassioli, R. Dinshaw, P. C. Arpin, G. D. Scholes, J. Roy. Soc. Interface 2014, 11.

[6] D. Liang, J. Almeida, Appl. Opt. 2012, 51, 6382.

[7] A. Durán, J. M. Monteagudo, Water Res. 2007, 41, 690.

[8] A. A. Earp, C. B. Smith, J. Franklin, P. D. Swift, Sol. Energy Mater. Sol. Cells 2004, 84, 411.

[9] M. G. Debije, Adv. Funct. Mater. 2010, 20, 1498.

[10] C. Alkan, M. Şekerci, Ş. Kunç, Int. J. Hydrogen Energy 1995, 20, 17.

[11] A. Köck, E. Gornik, M. Hauser, W. Beinstingl, Appl. Phys. Lett. 1990, $57,2327$.

[12] J. Feng, T. Okamoto, S. Kawata, Appl. Phys. Lett. 2005, 87, 241109.

[13] N. Straathof, D. Osch, A. Schouten, X. Wang, J. Schouten, V. Hessel, T. Noël, J. Flow Chem. 2014, 4, 12.

[14] A. Nzihou, G. Flamant, B. Stanmore, Energy 2012, 42, 121.

[15] D. Barlev, R. Vidu, P. Stroeve, Sol. Energy Mater. Sol. Cells 2011, 95, 2703.

[16] W. Yao, Y. S. Zhao, Nanoscale 2014, 6, 3467.

[17] E. Hecht, Optics, 4th Edition, Addison Wesley, San Francisco 2002.

[18] F. Hao, M. Zhang, Q. Wang, J. Wang, R. Wang, H. Ge, J. Opt. Soc. Am. B 2012, 29, 2255

[19] T. Ishigure, Y. Takeyoshi, Opt. Express 2007, 15, 5843.

[20] A. P. H. J. Schenning, F. B. G. Benneker, H. P. M. Geurts, X. Y. Liu, R. J. M. Nolte, J. Am. Chem. Soc. 1996, 118, 8549.

[21] T. J. Cui, R. Liu, D. R. Smith, in Metamaterials: Theory, Design, and Applications, (Eds: T. J. Cui, D. Smith, R. Liu), Springer, New York, 2010, 1.

[22] S. Fukuzumi, K. Ohkubo, T. Suenobu, Acc. Chem. Res. 2014, 47, 1455.

[23] H. Ries, J. Opt. Soc. Am. 1982, 72, 380.

[24] a) W. H. Weber, J. Lambe, Appl. Opt. 1976, 15, 2299; b) A. Goetzberger, W. Greubel, Appl. Phys. 1977, 14, 123.

[25] M. G. Debije, P. P. C. Verbunt, Adv. Energy Mater. 2012, 2, 12.

[26] a) L. H. Slooff, E. E. Bende, A. R. Burgers, T. Budel, M. Pravettoni, R. P. Kenny, E. D. Dunlop, A. Büchtemann, Phys. Status Solidi - $R$ 2008, 2, 257; b) J. C. Goldschmidt, M. Peters, A. Bösch, H. Helmers, F. Dimroth, S. W. Glunz, G. P. Willeke, Sol. Energy Mater. Sol. Cells 2009, 93, 176.

[27] J. A. Delaire, K. Nakatani, Chem. Rev. 2000, 100, 1817.

[28] P. P. C. Verbunt, A. Kaiser, K. Hermans, C. W. M. Bastiaansen, D. J. Broer, M. G. Debije, Adv. Funct. Mater. 2009, 19, 2714.

[29] a) C. L. Mulder, P. D. Reusswig, A. P. Beyler, H. Kim, C. Rotschild, M. A. Baldo, Opt. Express 2010, 18, A91; b) R. W. MacQueen, Y. Y. Cheng, R. G. C. R. Clady, T. W. Schmidt, Opt. Express 2010, 18, A161

[30] A. M. Kendhale, A. P. H. J. Schenning, M. G. Debije, J. Mater. Chem. A 2013, 7, 229.

[31] J. ter Schiphorst, A. M. Kendhale, M. G. Debije, C. Menelaou, L. M. Herz, A. P. H. J. Schenning, Chem. Mater. 2014, 26, 3876.

[32] M. G. Debije, C. Menelaou, L. M. Herz, A. P. H. J. Schenning, Adv. Opt. Mater. 2014, 2, 687.

[33] D. Dasgupta, A. M. Kendhale, M. G. Debije, J. ter Schphorst, I. K. Shishmanova, G. Portale, A. P. H. J. Schenning, ChemistryOpen 2014, 3, 138

[34] L. H. J. De Haan, C. Sanchez-Somolinos, C. M. W. Bastiaansen, A. P. H. J. Schenning, D. J. Broer, Angew. Chem. Int. Ed. 2012, 51, 12469.

[35] B. Bahadur, R. K. Sarna, V. G. Bhide, Mol. Cryst. Liq. Cryst. 1982, 72, 139. 